\title{
EFEITO DA PLANTA MATRIZ, ESTAÇÃO DO ANO E AMBIENTE DE CULTIVO NA MINIESTAQUIA DE Pinus radiata
}

\author{
Paula Rachel Rabelo Corrêa ${ }^{1}$, Bruno Schultz ${ }^{2}$, Celso Garcia Auer $^{3}$, Antonio Rioyei Higa ${ }^{4}$ \\ ${ }^{1}$ Fundação de Ensino e Pesquisa do Sul de Minas, Varginha, Minas Gerais, Paraná, Brasil - rabelocorrea @ hotmail.com \\ ${ }^{2}$ Instituto Nacional de Pesquisas Espaciais, São José dos Campos, São Paulo, Brasil - schultz.florestal@gmail.com \\ ${ }^{3}$ Empresa Brasileira de Pesquisa Agropecuária, Colombo, Paraná, Brasil - celso.auer@embrapa.br \\ ${ }^{4}$ Universidade Federal do Paraná, Departamento de Ciências Florestais, Curitiba, Paraná, Brasil - higa@ufpr.br
}

Recebido para publicação: 19/06/2013 - Aceito para publicação: 30/04/2014

\begin{abstract}
Resumo
A estaquia de genótipos superiores de Pinus radiata é uma prática comum na silvicultura. Para sua utilização no Brasil, protocolos de propagação precisam ser estabelecidos. Este trabalho avaliou a miniestaquia aplicada à produção de mudas da espécie, estudando a posição de coleta de broto na planta matriz, a estação do ano e o minijardim. Plantas matrizes seminais, com $1 \mathrm{~m}$ de altura e 1,5 anos de idade, foram utilizadas para a produção de miniestacas. Três ensaios consecutivos foram feitos: (i) o enraizamento das miniestacas coletadas de três posições nas matrizes (topo, intermediário e basal), (ii) a influência do minijardim (vaso, canaletão e campo) no desenvolvimento de minicepas e (iii) o efeito da estação do ano (inverno, primavera e verão) sobre o desenvolvimento de miniestacas coletadas de minicepas no canaletão, no vaso e em campo. As miniestacas coletadas da região intermediária das matrizes, com 1,5 anos de idade, apresentaram maior enraizamento do que as coletadas no topo e na região basal. As melhores estações para o desenvolvimento dos brotos foram inverno e primavera, em ambientes de vaso e campo. O verão promoveu melhor desenvolvimento das miniestacas em casa de vegetação, a partir de matrizes cultivadas em canaletão.
\end{abstract}

Palavras-chave: Clonagem; conífera; produção de muda; propagação vegetativa.

\begin{abstract}
Effect of matrix plant, season and minigarden on Pinus radiata minicutting. Cutting of superior genotypes of Pinus radiata is current in forestry. For such practice in Brazil, protocols of propagation need to be established. We evaluated the mini-cutting applied to seedling production, focusing the collection point in matrix plant, season, and minigarden. We used seminal matrix $1 \mathrm{~m}$ height and 1.5 years old for mini-cutting production. Three consecutive trials were made: (i) the rooting of minicuttings collected from three points in the matrix (top, intermediate and basal), (ii) the influence of minigarden (pot, gutters and field) in development of rooted, and (iii) the effect of season (winter, spring and summer) on the development of rooted cuttings collected in pot, gutters and field. The mini-cuttings collected from the intermediate region of the 1.5 years old seedlings matrices had higher rooting than those collected from the top and basal region. The best time for the development of buds was winter and spring in pots as well as field environments. Summer promoted the best development of mini-cuttings, in greenhouse, from matrix plant grown in gutters.

Keywords: Cloning; conifer; seedling production, vegetative propagation.
\end{abstract}

\section{INTRODUÇÃO}

Pinus radiata D. Don é a espécie florestal exótica mais plantada em todo o mundo, devido ao seu rápido crescimento, às qualidades excepcionais de sua polpa na fabricação de papel e à sua capacidade em produzir maior volume de madeira por área em um menor espaço de tempo (MCDONALD; LAACKE, 1990; ROGERS, 2002; FORESTS NSW PLANTED FORESTS, 2008). Plantios comerciais podem ser encontrados em vários países do hemisfério Sul, como Chile, Austrália, Nova Zelândia e África do Sul. No entanto, apesar de suas qualidades superiores, o Pinus radiata não é plantado comercialmente no Brasil. Esse fato decorre de sua baixa adaptação aos climas quentes e úmidos, que favorece o desenvolvimento do fungo Diplodia pinea (Desmaz.) J. Kickx, principal fator limitante da expansão dos

FLORESTA, Curitiba, PR, v. 45, n. 1, p. 65 - 74, jan. / mar. 2015

Corrêa, P. R. R. et al.

ISSN eletrônico 1982-4688 / ISSN impresso 0015-3826

DOI: $10.5380 /$ rf.v45i1.32793 
plantios comerciais dessa espécie (SHIMUZI, 2001).

Um dos métodos de controle de Diplodia pinea é a seleção de indivíduos resistentes e adaptados às condições locais (CORRÊA et al., 2012). Por meio do melhoramento florestal, é possível selecionar material genético resistente ao fungo e com grande capacidade produtiva, para o estabelecimento de plantios clonais via propagação vegetativa. Essa estratégia está sendo utilizada com grande sucesso nos plantios comerciais (XAVIER et al., 2009), pois permite a fixação de genótipos superiores a um menor custo (RESENDE, 2002).

A produção de mudas por meio da estaquia de genótipos superiores de Pinus radiata é uma prática estabelecida para os plantios comerciais da espécie, com plantas com até 15 anos de idade servindo como fonte de propágulos. Apesar de Pinus radiata ser conhecido como uma planta lenhosa de fácil propagação vegetativa, conforme relatado por Cameron (1968), no Brasil ainda não existe um protocolo estabelecido para essa finalidade (HIGA; SILVA, 2006). Desse modo, a presente pesquisa teve como objetivo avaliar o efeito da posição de coleta de broto na planta matriz, da estação do ano e de ambientes de cultivo no desenvolvimento de miniestacas de Pinus radiata.

\section{MATERIAL E MÉTODOS}

\section{Localização da área experimental}

Este estudo foi realizado em casa de vegetação do Laboratório de Melhoramento Florestal (LAMEF), Universidade Federal do Paraná, localizada em Curitiba, PR, conforme figura 1.

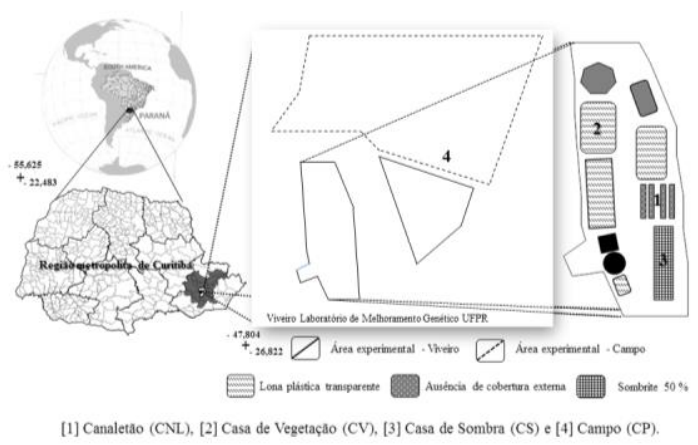

Figura 1. Localização dos ensaios de miniestaquia com Pinus radiata, Curitiba, PR.

Figure 1. Location of minicutting experiments of Pinus radiate, Curitiba, PR.

A série histórica, com dados metereológicos abrangendo os períodos da época da realização dos experimentos, foi obtida na estação CURITIBA, PR (OMM: 83842), localizada a 923,5 m de altitude e apresentada na figura 2 .

Plantas matrizes de Pinus radiata foram produzidas a partir de mudas formadas com sementes de progênies de polinização controlada, procedentes da Nova Zelândia. As mudas foram cultivadas em tubetes de polietileno com volume de $55 \mathrm{~cm}^{3}$ preenchidos com substrato comercial à base de vermiculita e casca de pínus (9:1, v/v), sem fertirrigação. Após o desenvolvimento inicial, as mudas foram plantadas em vasos de $25 \mathrm{~L}$ com o mesmo substrato e mantidas em estufa com sombrite de $50 \%$ de sombreamento.

$\mathrm{Na}$ montagem dos ensaios, as matrizes estavam com aproximadamente $1 \mathrm{~m}$ de altura e 1,5 anos de idade, recebiam duas adubações de $25 \mathrm{~g}$ por vaso com formulação 12-14-8 $\left(\mathrm{N}-\mathrm{P}_{2} \mathrm{O}_{5}-\mathrm{K}_{2} \mathrm{O}\right)$ por mês. As miniestacas foram coletadas com tesoura desinfestada em álcool $70 \%$, com o corte realizado na forma de bisel, com tamanhos que variaram entre 2 e $8 \mathrm{~cm}$ e plantadas em tubetes de polipropileno com $55 \mathrm{~cm}^{3}$, preenchidos com o mesmo substrato à base de vermiculita e casca de pínus. As miniestacas permaneceram em casa de vegetação com sistema de nebulização intermitente por cerca de 120 dias. O estudo foi dividido em três ensaios consecutivos, conforme apresentado na figura 3.

\section{Avaliação do enraizamento das miniestacas coletadas de diferentes posições da planta matriz}

Esse ensaio analisou o enraizamento adventício entre as miniestacas coletadas de diferentes posições nas matrizes. Foram coletadas 324 miniestacas de 10 progênies de Pinus radiata, com 
aproximadamente $5 \mathrm{~cm}$ de comprimento. A hipótese testada baseou-se na existência de diferenças na capacidade de enraizamento das miniestacas, dependência da posição de coleta e entre as progênies. As miniestacas foram dispostas nas bandejas multicelulares de polipropileno em delineamento de blocos ao acaso com três tratamentos, nove plantas por parcela, doze blocos em arranjo fatorial. O experimento foi mantido em casa de vegetação aclimatizada com temperatura média de $22{ }^{\circ} \mathrm{C}$, com quatro aspersões diárias de aproximadamente $250 \mathrm{~mL}$ de água por vaso.

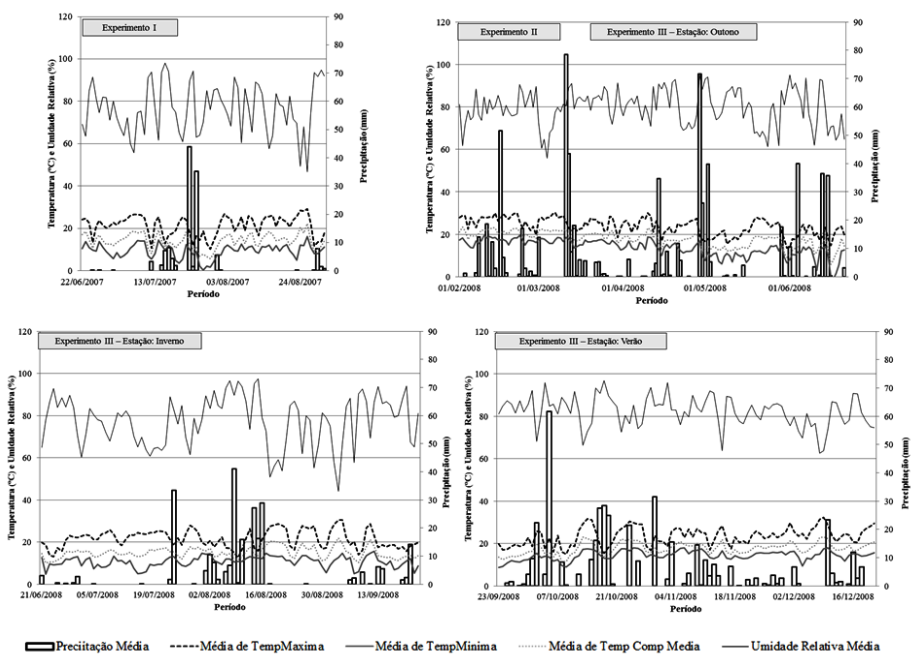

Figura 2. Série temporal de dados diários: temperatura média, máxima, mínima, umidade relativa e precipitação do período que compreendeu 21/06/2008 a 30/12/2009. A estação meteorológica está localizada a $2 \mathrm{~km}$ do local de estudo (25,43 S; 49,26 W).

Figure 2. Time series data daily: temperature average, maximum, minimum, relative humidity e rainfall for the period understood in 21/06/2008 to 30/12/2009. Weather station is located $2 \mathrm{~km}$ from the study area $(25,43 \mathrm{~S} ; 49,26 \mathrm{~W})$.

Fonte: Instituto Nacional de Meteorologia (2014), adaptado pelos autores.

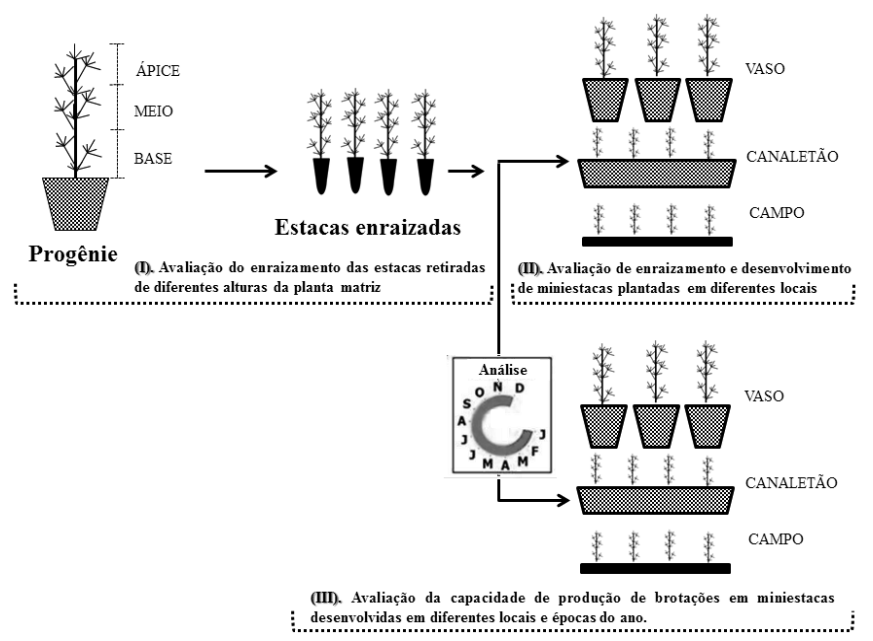

Figura 3. Diagrama dos ensaios com miniestaquia de Pinus radiata. LAMEF, UFPR. Curitiba, PR.

Figure 3. Diagram of the trials with Pinus radiata minicutting. LAMEF, UFPR. Curitiba, PR.

O ensaio foi realizado entre os meses de julho e setembro de 2007, sem a aplicação de fitohormônio para induzir o enraizamento. As miniestacas foram analisadas quanto ao potencial de enraizamento, após 120 dias de instalação do experimento, usando-se como referência de adequado enraizamento as raízes emitidas na base do tubete e que mantiveram uma formação radicial estruturada.

FLORESTA, Curitiba, PR, v. 45, n. 1, p. 65 - 74, jan. / mar. 2015.

Corrêa, P. R. R. et al.

ISSN eletrônico 1982-4688 / ISSN impresso 0015-3826 
Avaliação do desenvolvimento de miniestacas de progênies de Pinus radiata plantados em canaletão, vasos e no campo

Esse ensaio analisou o efeito que o minijardim pode ter no desenvolvimento de miniestacas de Pinus radiata. A hipótese baseou-se na existência de diferenças no desenvolvimento das miniestacas dependentes do ambiente onde elas foram colocadas. Para testar essa hipótese, em fevereiro de 2008, as 90 estacas com melhor desenvolvimento no experimento anterior, ou seja, aquelas que se apresentavam saudáveis e cujo comprimento estava situado acima de $10 \mathrm{~cm}$ de altura, foram transplantadas para vaso, canaletão e campo em espaçamento de $10 \times 20 \mathrm{~cm}$ no canaletão, 50 × $50 \mathrm{~cm}$ no campo e somente uma estaca por vaso.O experimento foi montado em delineamento de blocos ao acaso, uma planta por parcela com três blocos em arranjo fatorial.

Os vasos e canaletões foram preenchidos com substrato à base de vermicomposto, com adubação de cobertura ( $25 \mathrm{~g}$ por vaso e $100 \mathrm{~g}$ por canaletão) com formulação 12-14-8 $\left(\mathrm{N}-\mathrm{P}_{2} \mathrm{O}_{5}-\mathrm{K}_{2} \mathrm{O}\right)$ pós-plantio. No campo, foram aplicados $100 \mathrm{~g}$ de adubo NPK 12-14-8 ao lado de cada estaca, no plantio. Os vasos foram mantidos em casa de vegetação sob cobertura plástica e os canaletões foram mantidos ao ar livre. Nesses dois ambientes, as estacas eram irrigadas automaticamente quatro vezes ao dia durante 15 segundos. As estacas plantadas no campo não receberam irrigação. Nesse período, as estacas receberam, nos três ambientes, $100 \mathrm{~mL}$ de fertirrigação contendo 92 de N, 36 de $\mathrm{P}, 69$ de K, 81 de Ca, 21 de $\mathrm{Mg}, 34$ de S, 4,2 de Fe, 0,3 de Mn, 0,2 de Zn e 0,4 de B (concentrações em mg. $\mathrm{L}^{-1}$ ), para indução de brotação baseada em estudo de Andrejow (2006) e Epstein e Bloom (2006). Após 95 dias, foram coletadas as miniestacas para avaliação dos minijardins clonais, com a montagem do próximo experimento.

\section{Avaliação da capacidade de produção de brotações em minicepas desenvolvidas em diferentes locais e estações do ano}

Esse ensaio foi realizado com o objetivo de avaliar a capacidade de minicepas de Pinus radiata desenvolvidas no canaletão, vaso e no campo de produzirem miniestacas em diferentes estações do ano. A hipótese testada baseou-se na existência de diferenças entre os locais de estabelecimento do minijardim e entre as estações do ano em que as miniestacas foram coletadas. Para tanto, foram retiradas 30 miniestacas com $2 \mathrm{~cm}$ de comprimento da região mediana de cada minicepa e plantadas em tubetes com substrato comercial à base de vermiculita e casca de pínus $(9: 1, \mathrm{v} / \mathrm{v})$ no inverno $(20 / 05 / 2008)$, primavera (20/09/2008) e verão (20/12/2008), em delineamento de blocos ao acaso, com quatro blocos e 16 plantas por parcela. As miniestacas foram mantidas em casa de vegetação aclimatizada, com quatro aspersões diárias, temperatura média de $22{ }^{\circ} \mathrm{C}$ e irrigação de $250 \mathrm{~mL}$ por dia. Além disso, as miniestacas receberam, de acordo com os estudos de Epstein e Bloom (2006) e formulação recomendada por Andrejow (2006), $100 \mathrm{~mL}$ de uma solução contendo 91 de N, 13 de P, 132 de K, 32 de Ca, 16 de Mg, 16 de S, 1,1 de Fe, 1,9 de Mn, 0,5 de Zn, 0,1 de $\mathrm{Cu}$ e 0,3 de B (concentrações em mg. $\mathrm{L}^{-1}$ ) aplicadas manualmente duas vezes por semana para indução do enraizamento.

Após 30 dias, as miniestacas foram avaliadas quanto ao desenvolvimento. Essa avaliação foi realizada medindo-se as alturas iniciais e finais de cada estaca, com um paquímetro digital, e calculando o incremento obtido para cada miniestaca acima dos dois $\mathrm{cm}$ iniciais.

\section{Análises estatísticas}

A análise estatística foi realizada com auxílio do programa Excel. O teste de Bartlett avaliou a homogeneidade das variâncias e, quando heterogêneas, os dados foram transformados para arcseno $\sqrt{\mathrm{P}} / 100$. Após o teste de Bartlett, as médias dos tratamentos foram analisadas por meio do teste de diferença mínima significativa - DMS ( $p<0,05)$.

\section{RESULTADOS E DISCUSSÃO}

Avaliação do enraizamento das miniestacas coletadas de diferentes posições da planta matriz

Houve adequado enraizamento das miniestacas $(76,6 \%)$ coletadas das plantas jovens de Pinus radiata (Tabela 1). A região mediana das plantas matrizes revelou-se como melhor fonte doadora de propágulos para o enraizamento, significativamente superior à região do colo. 
Tabela 1. Enraizamento (\%) das miniestacas coletadas da região apical, mediana e do colo de mudas de Pinus radiata.

Table 1. Rooting (\%) of minicuttings obtained from top, intermediate and collar region of Pinus radiata seedlings.

\begin{tabular}{lc}
\hline Posição na planta matriz & Enraizamento $(\%) *$ \\
\hline Ápice & $78,7 \mathrm{ab}$ \\
Mediana & $82,5 \mathrm{a}$ \\
Colo & $68,5 \mathrm{~b}$ \\
Média & 76,6 \\
\hline CV $(\%)$ & 2,1 \\
\hline *Médias seguidas por letras iguais dentro da coluna não apresentam diferença significativa entre \\
si pelo teste DMS (p < 0,05). Cada valor refere-se à média de 9 plantas (miniestacas).
\end{tabular}

Segundo Hartmann et al. (2011), estacas retiradas de diferentes porções do ramo diferem na capacidade rizogênica, pois o teor endógeno de hormônios e reservas varia de acordo com a idade fisiológica e cronológica dos tecidos, ocasionando diversas respostas morfogenéticas (XAVIER et al., 2009). De acordo com Hinojosa (2000), a concentração da auxina diminui ao longo do caule a partir do ápice caulinar. As auxinas promovem a formação de raízes laterais e adventícias, por agirem em grupos de células especiais do periciclo, estimulando-as a se dividirem (HINOJOSA, 2000).

No entanto, dependendo do tipo de estaca, devido à maior maturação fisiológica, a base dos ramos normalmente é mais favorável ao enraizamento que à parte superior (PAIVA; GOMES, 1995). Andrejow (2006) avaliou diferentes substratos e doses nutritivas para enraizamento de estacas de Pinus taeda. Usando substrato à base de vermiculita e indutores de enraizamento, o autor observou $64,3 \%$ de enraizamento em brotações jovens de Pinus taeda. Bertoloti et al. (1981) verificaram, em eucalipto, que estacas oriundas de material mais lignificado apresentaram melhores resultados, tanto na brotação das gemas como no enraizamento das estacas. No entanto, segundo esses autores, as estacas coletadas na região do ponteiro secavam após alguns dias, provavelmente por apresentarem poucas reservas em seus órgãos (folhas e caule). Nesse estudo, o maior índice de enraizamento das miniestacas retiradas da região mediana da planta matriz deve estar relacionado à maturidade do tecido nessa porção da planta, pois não houve a adição de reguladores de crescimento ao enraizamento das miniestacas.

Segundo Silva (1998), os ramos laterais enraízam mais rapidamente que os ramos apicais, em virtude de contarem com maior disponibilidade de carboidratos. Fato similar, segundo esse mesmo autor, ocorre com a porção basal de ramos em relação à porção terminal. Estudos realizados por Penchel et al. (1995) demonstraram resultados semelhantes e destacaram como principais resultados o aumento médio da porcentagem de enraizamento, de $11,6 \%$ e $7,6 \%$, em material preparado a partir de ramos plagiotrópicos em relação aos ramos ortotrópicos e na capacidade de enraizamento de miniestacas em relação a estacas padrão, respectivamente. Esses autores constataram que tanto a taxa de enraizamento quanto o número de raízes por estacas tende a aumentar em miniestacas obtidas da parte mediana ou basal da brotação para diversos clones estudados.

\section{Avaliação do desenvolvimento de miniestacas de progênies de Pinus radiata plantados em canaletão, vasos e no campo}

Os resultados revelaram que o desenvolvimento das miniestacas diferiu significativamente entre os diferentes ambientes (Tabela 2). O comprimento das miniestacas nas mudas no campo e nos vasos foi semelhante. Contudo, houve diferença significativa no desenvolvimento entre as brotações dos vasos e do canaletão, sendo que o melhor crescimento foi nos vasos.

Tabela 2. Crescimento $(\mathrm{cm})$ de miniestacas de Pinus radiata plantadas em três ambientes.

Table 2. Growth $(\mathrm{cm})$ of Pinus radiata minicuttings planted in three environments.

\begin{tabular}{lc}
\hline Tipo de minijardim & Crescimento* $(\mathbf{c m})$ \\
\hline Campo & $1,17 \mathrm{ab}$ \\
Vaso & $1,51 \mathrm{a}$ \\
Canaletão & $0,34 \mathrm{~b}$ \\
\hline Média & 1,01 \\
\hline CV $(\%)$ & 13,8 \\
\hline
\end{tabular}

Médias seguidas por letras iguais dentro da coluna não apresentam diferença significativa entre si pelo teste DMS $(\mathrm{p}<0,05)$. *Cada valor é média de 30 plantas.

FLORESTA, Curitiba, PR, v. 45, n. 1, p. 65 - 74, jan. / mar. 2015.

Corrêa, P. R. R. et al.

ISSN eletrônico 1982-4688 / ISSN impresso 0015-3826 
Comparando os estudos de Xavier e Comério (1996), Wendling et al. (2000) e Brondani et al. (2012b) com Eucalyptus, evidencia-se que as minicepas emitem brotações com mais de $5 \mathrm{~cm}$ em uma semana. Neste estudo com Pinus radiata, os resultados revelaram que, nas condições avaliadas, foram necessários 3 meses para emissões de brotações com tamanho considerado ideal para o plantio das miniestaquias (5 cm). Fato semelhante foi observado por Andrejow (2006), em que minicepas de Pinus taeda, controladas com altas taxas de fertirrigações, aos sete dias, também não apresentaram incremento superior a $5 \mathrm{~cm}$. Fica evidente que o tempo para emissão de novos propágulos pelas coníferas é maior do que para as folhosas. Nesse sentido, estudos com hormônios que promovam o alongamento caulinar podem ser uma alternativa para acelerar a produção de brotos em coníferas (TAYZ; ZEIGER, 2004). Alfenas et al. (2009), no entanto, consideraram que as condições nutricionais e a forma de manejo são os fatores limitantes para o sucesso de um jardim clonal, principalmente de coníferas.

Andrejow (2006) comentou que Pinus taeda exige altas taxas de NPK para emissão de propágulos. Molina et al. (1987) verificaram que o fósforo desempenha o papel de maior importância no crescimento em altura e produção de matéria seca foliar e sobrevivência do Pinus maestrensis em condições de viveiro. Portanto, estudos sobre a adubação ideal para minicepas de Pinus radiata podem melhorar a taxa produtiva de propágulos por período de coleta, além de influenciar o enraizamento. Andrejow (2006) reforçou que, além da nutrição, outro fator importante ligado à produção dos propágulos refere-se ao substrato em que a planta matriz foi plantada.

Higashi e Silveira (2004) comentaram que o substrato mais utilizado para miniestaquia é a areia inerte, mais comumente encontrado em viveiros clonais de eucalipto, mas complementaram que essa é também uma das principais diferenças entre o minijardim clonal de Pinus e o de eucalipto, onde o substrato orgânico tem apresentado superioridade em relação a substratos inertes, como a areia lavada. No entanto, de acordo com Malavolta (2006), a areia favorece a capacidade de troca catiônica (CTC) entre a raiz da planta e a solução salina. Espécies de pínus possuem baixa CTC (50 a $300 \mathrm{mmol}_{\mathrm{c}} / \mathrm{kg}^{-1}$ ), em comparação às dicotiledôneas (geralmente de $200 \mathrm{a} 900 \mathrm{mmol}_{\mathcal{C}} / \mathrm{kg}^{-1}$ ), fato que dificulta a troca de cátions entre solos argilosos e a raiz da planta.

Avaliação da capacidade de produção de brotações em miniestacas de progênies de Pinus radiata desenvolvidas em canaletões, vaso e no campo em diferentes estações do ano

Houve diferença significativa entre progênies e interação significativa no desenvolvimento das progênies nos meses de inverno e primavera (Tabela 3). Mas não houve interação significativa entre as progênies e a época de coleta das miniestaquias $(\mathrm{p}<0,01)$, indicando que seus efeitos são independentes.

Tabela 3. Análise de variância dos fatores progênies (P), ambiente (A) e estação de coleta de miniestacas de Pinus radiata.

Table 3. Variance analysis of provenances (P), environment (A) and collect season of Pinus radiata minicutting.

\begin{tabular}{lccc}
\hline Fonte de variação & GL & QM & $\boldsymbol{\alpha}$ \\
\hline Progênie & 9 & 11,4 & $0,00^{* *}$ \\
Época de coleta & 2 & 0,41 & $0,92^{\text {ns }}$ \\
Progênies inverno & 9 & 0,82 & $0,28^{\text {ns }}$ \\
Progênies primavera & 9 & 0,88 & $0,50^{\text {ns }}$ \\
Progênies verão & 9 & 0,32 & $0,12^{\text {ns }}$ \\
Ambiente inverno & 2 & 7,94 & $0,00^{* *}$ \\
Ambiente primavera & 2 & 13,66 & $0,00^{* *}$ \\
Ambiente verão & 2 & 0,58 & $0,89^{\text {ns }}$ \\
P x A inverno & 18 & 0,49 & $0,94^{\text {ns }}$ \\
P x A primavera & 18 & 0,86 & $0,57^{\text {ns }}$ \\
P x A verão & 18 & 11,4 & $0,00^{\text {ns }}$ \\
\hline${ }^{*}$ significativo $(\mathrm{p}<0,05) ;{ }^{* *}$ significativo $(\mathrm{p}<0,01) ;{ }^{\text {ns }}$ não significativo. & &
\end{tabular}

Andrejow (2006), analisando a estaquia de Pinus taeda, salientou que as estacas devem ser coletadas no período de repouso vegetativo, o qual é variável de acordo com a espécie da planta. Nesse período ocorre o equilíbrio de carboidratos/nitrogênio, que pode afetar a iniciação e o desenvolvimento das raízes em eucalipto (SILVA, 1998; BRONDANI et al., 2012a). Nesse contexto, Alcântara (2005) verificou ser o inverno a estação propícia para coletar miniestacas de Pinus taeda, provavelmente em 
função do período de dormência, e o outono a estação menos indicada, fato também constatado por Foster et al. (2000).

No entanto, os resultados obtidos neste estudo não encontraram interação significativa entre as épocas de coleta e o desenvolvimento das miniestacas. Assim, não houve correlação entre o desenvolvimento das matrizes com o desenvolvimento das miniestacas em casa de vegetação, com relação à época do ano.

Por outro lado verificou-se que existiram diferenças significativas no incremento médio em altura entre as miniestacas desenvolvidas em casa de vegetação quando coletadas das matrizes no campo e no canaletão, sendo que as que foram coletadas do canaletão desenvolveram-se melhor, principalmente no verão (Tabela 4).

Tabela 4. Incremento médio em altura $(\mathrm{cm})$ das miniestacas de Pinus radiata de acordo com a origem e a estação de coleta.

Table 4. Average height increment $(\mathrm{cm})$ of Pinus radiata minicuttings according to origin and collect season.

\begin{tabular}{lcccc}
\hline Estação do ano & Campo & Vaso & Canaletão & Médias* \\
\hline Inverno & 1,07 & 0,68 & 0,56 & $0,77 \mathrm{~b}$ \\
Primavera & 0,69 & 0,75 & 2,42 & $1,28 \mathrm{~b}$ \\
Verão & 1,28 & 1,91 & 2,18 & $1,79 \mathrm{a}$ \\
\hline Médias & $1,01 \mathrm{~B}$ & $1,11 \mathrm{AB}$ & $1,72 \mathrm{~A}$ & 0,73 \\
\hline Ḿ́dias
\end{tabular}

Médias seguidas por letras iguais maiúsculas dentro da linha não apresentam diferença significativa entre si pelo teste DMS $(\mathrm{p}<0,05)$. *Cada valor é média de 16 plantas.

Provavelmente, nos ambientes vasos e canaletão, as progênies foram mantidas com melhores taxas nutricionais, por conta de estarem em ambiente fechado sujeito a menores perdas por lixiviação. Se essa condição for verdadeira, refletiu apenas no desenvolvimento das miniestacas, não refletindo no desempenho das matrizes, como seria esperado. Malavolta (2006) comentou que, além da lixiviação, a perda de nutrientes pode ocorrer pela imobilização de $\mathrm{P}$ e K, quando ocorre excesso de $\mathrm{N}$ na solução salina.

Malavasi (1994) afirmou que, dentro de certos limites, o estado nutricional do propágulo possui maior influência no crescimento do que na iniciação radicular, sugerindo que a influência da nutrição mineral na iniciação radicular é altamente dependente dos níveis iniciais dentro daquela porção da estaca onde as raízes serão induzidas. De acordo com o mesmo autor, o estado nutricional do vegetal pode também atuar em sinergia com vários fatores que afetam o crescimento e vigor pós-propagação.

Mesmo com todas as dificuldades e limitações em obter índices de enraizamento em escala comercial com o gênero Pinus, é necessário persistir nos estudos para evolução das técnicas, visando maximizar o enraizamento de estacas e miniestacas em espécies florestais, porque a metodologia de propagação vegetativa é ainda o maior avanço dentro de um programa de melhoramento. Nesse cenário, a exemplo do aconteceu com o Eucalyptus, em que a multiplicação clonal permitiu a manutenção das características da planta-mãe, de modo a obter talhões uniformes, de rápido crescimento e matéria-prima homogênea, toda a tecnologia que facilite ou até mesmo viabilize a produção de clones é atrativa.

Cabe ainda ressaltar que a dificuldade em propagar vegetativamente as espécies de Pinus sempre foi um gargalo na silvicultura brasileira, e provavelmente foi um dos motivos da desmotivação em aumentar as áreas de plantio do gênero no Brasil. Graça et al. (1999), estudando Eucalyptus benthamii, comentaram que as estacas possuem baixa capacidade de enraizamento. Quando a estaquia foi realizada na primavera, o resultado de enraizamento foi 32,3\%, e no outono, 26,3\%. Alguns estudos que utilizaram híbridos de Eucalyptus benthamii Maiden at Cambage x Eucalyptus dunnii Maiden em sistema semihidropônico para enraizamento não obtiveram mais de 55\% de enraizamento para genótipos selecionados na primeira coleta de propágulos da planta matriz, utilizando regulador de crescimento (BRONDANI et al., 2010).

\section{CONCLUSÕES}

- O estudo com miniestacas de Pinus radiata indicou que brotações coletadas da porção mediana do caule de matrizes apresentam maior percentual de enraizamento.

- Com base nos resultados, a produção de miniestacas pode ser feita em casa de vegetação, durante o verão, a partir de brotações coletadas em canaletão fertirrigado, no final do inverno. 


\section{AGRADECIMENTOS}

segundo autor.

À CAPES, pela bolsa de doutorado do primeiro autor, e ao CNPq, pela bolsa de doutorado do REFERÊNCIAS

ALCÂNTARA, G. B. Miniestaquia de Pinus taeda L. 64 f. Dissertação (Mestrado em Botânica) Universidade Federal do Paraná, Curitiba, 2005.

ANDREJOW, G. M. P. Minijardim clonal de Pinus taeda L. 92 f. Dissertação (Mestrado em Engenharia Florestal) - Universidade Federal do Paraná, Curitiba, 2006.

ALFENAS, A. C.; ZAUZA, E. A. V.; MAFIA, R. G.; ASSIS, T. F. Clonagem e doenças do eucalipto. 2. ed. Viçosa: Editora UFV. 2009. 500 p.

BERTOLOTI, G.; MORA, A. L.; GONÇALVES, A. N. Enraizamento de estacas de Eucalyptus camaldulensis e Eucalyptus tereticornis. Boletim Informativo IPEF, Piracicaba, v. 9, n. 28, p. 73 - 79, 1981.

BRONDANI, G. E.; GROSSI, F.; WENDLING, I.; DUTRA, L. F.; ARAÚJO, M. A. Aplicação de AIB para o enraizamento de miniestacas de Eucalyptus benthamii Maiden et Cambage x Eucalyptus dunnii Maiden. Acta Scientiarum, Maringá, v. 32, n. 1, p. 667 - 677, 2010.

BRONDANI, G. E.; HOFFMANN, J. M. E.; GONÇALVES, A. N.; ALMEIDA, M. Determinação do teor de carboidratos em minicepas de Eucalyptus benthamii. Journal of Biotechnology and Biodiversity, Gurupi, v. 3, n. 1, p. 51 - 60, 2012a.

BRONDANI, G. E.; WENDLING, I., BRONDANI, A. E.; ARAÚJO, M. A.; SILVA, A. L. L. da; GONÇALVES, A. N. Dynamics of adventitious rooting in mini-cuttings of Eucalyptus benthamii $\mathrm{x}$ Eucalyptus dunnii. Acta Scientiarum, Maringá, v. 34, n. 2, p. 169 - 178, 2012 b.

CAMERON, R. J. The propagation of Pinus radiata by cuttings: influences affecting the rooting of cuttings. New Zealand Journal of Forestry, Rotorua, v. 13, n. 1, p. 78 - 89, 1968.

CORRÊA, P. R. R.; AUER, C. G.; SANTOS, A. F. dos; HIGA, A. R. Seleção precoce de progênies de Pinus radiata a Sphaeropsis sapinea. Ciência Florestal, Santa Maria, v. 22, n. 2, p. 275 - 281, 2012.

EPSTEIN, E.; BLOOM, A. J. Nutrição mineral de plantas: Princípios e perspectivas. 2. ed. Londrina: Editora Planta, 2006. 401 p.

FORESTS NSW INFORMATION CENTRE. Radiata pine "The remarkable pine". PRIMEFACT 646 Forests NSW Planted Forests, 2008. Disponível em: <http://www.forestrycorporation.com.au/_data/asse ts/pdf_file/0017/420920/Radiata-pine-the-remarkable-pine.pdf>. Acesso em: 17/03/2014.

FOSTER, G. S.; STELZER, H. E.; MCRAE, J. B. Loblolly pine cutting morphological traits: effects on rooting and field performance. New Forest, Dordrecht, v. 19, n. 3, p. 291 - 306, 2000.

GRAÇA, M. E. C.; SHIMIZU, J. Y.; TAVARES, F. R. Capacidade de rebrota e de enraizamento de Eucalyptus benthamii. Boletim de Pesquisa Florestal, Colombo, n. 39, p. 135 - 138, 1999.

HARTMANN, H. T.; KESTER, D. E.; DAVIES JÚNIOR, F. T.; GENEVE, R. L. Plant propagation: principles and practices. 8th. ed. Boston: Prentice-Hall, 2011. 915 p.

HINOJOSA, G. F. Auxinas In: CID, L. P. B. Introdução aos hormônios vegetais. Brasília: Embrapa Recursos Genéticos e Biotecnologia. 2000. p. 15 - 53.

HIGA, A. R.; SILVA, L. D. Pomar de sementes de espécies florestais nativas. Curitiba: FUPEF, 2006. $226 \mathrm{p}$.

HIGASHI, E. N.; SILVEIRA, R. L. A. Fertirrigação em viveiros de mudas de Eucalyptus e Pinus. In: BOARETTO, A. E.; VILLAS BOAS, R. L.; SOUZA, W. F.; PARRA, L. R. V. Fertirrigação: teoria e prática. Piracicaba, v. 1, p. 677 - 725, 2004. 1 CD-ROM. 
INSTITUTO NACIONAL DE METEOROLOGIA. Banco de dados meteorológicos para ensino e pesquisa. 2014. Disponível em: <https://www.inmet.gov.br/portal/index>. Acesso em: 20/01/2014.

MCDOnAld, P. M.; LAACKE, R. J. Pinus radiata D. Don, Monterey Pine. 1990. Disponível em: <http://www.na.fs.fed.us/pubs/silvics_manual/Volume_1/pinus/radiata.htm>. Acesso em: 17/03/2014.

MALAVASI, U. C. Macropropagação vegetativa em coníferas: perspectivas biológicas e operacionais. Floresta e ambiente, Itaguaí, n. 1, p. 131 - 135, 1994.

MALAVOLTA, E. Manual de nutrição de plantas. São Paulo: Editora Ceres. 2006. 638 p.

MOLINA, G.; HERRERO, G.; YERO, L.; SANCHEZ, J.; LOBAINA, B. Efecto de NPK sobre las posturas de Pinus maestrensis em viveiro y en campo. Revista Florestal Baracoa, La Habana, v. 17, n. 2, p. 85 - 96, 1987.

PAIVA, H. N. de; GOMES, J. M. Propagação vegetativa de espécies florestais. Viçosa: Editora UFV. 1995. 40 p. (Boletim Técnico, 322).

PENCHEL, R. M.; NEVES, D. C.; CAMPINHOS, C. N.; EVANGELISTA, A. L.; DESCHAMPS, C. Otimização de parâmetros fisiológicos da propagação vegetativa por estaquia de matrizes elite de Eucalyptus. In CONGRESSO BRASILEIRO DE FISIOLOGIA VEGETAL, 5., Lavras, 1995. Resumos... Lavras: UFLA, 1995, p. 83.

RESENDE, M. D. V. Genética biométrica e estatística no melhoramento de plantas perenes. Brasília: Embrapa Informação Tecnológica. 2002. 975 p.

ROGERS, D. L. In situ genetic conservation of Monterey pine (Pinus radiata D. Don): Information and recommendations. Davis: University of California Division of Agriculture and Natural Resources. 2002. 92 p. Disponível em: <http://grcp.ucdavis.edu/publications/doc26pdf.htm>. Acesso em: 20/01/2014.

SILVA, O. R. Enraizamento de estacas de Eucalyptus grandis via sistema hidropônico. Dissertação (Mestrado em Engenharia Florestal) - Universidade Federal de Viçosa, Viçosa, 1998, 142 p.

SHIMIZU, J. Y. Memórias do "Workshop" sobre conservação e uso de recursos genéticos florestais (Paranaguá, PR, 2000). Embrapa Florestas, 1ํ edição, Colombo, 2001.

TAYZ, L.; ZEIGER, E. Fisiologia vegetal. 3. ed. Porto Alegre: Artmed. 2004. 719 p.

WENDLING, I.; XAVIER, A.; GOMES, J. M.; PIRES, I. E.; ANDRADE, H. B. Efeito do regulador de crescimento AIB na propagação de clones de Eucalyptus spp. por miniestaquia. Revista Árvore, Viçosa, v. 24, n. 2, p. 187 - 192, 2000.

XAVIER, A.; COMERIO, J. Microestaquia: uma maximização da micropropagação de Eucalyptus. Revista Árvore, Viçosa, v. 20, n. 1, p. 9 - 16, 1996.

XAVIER, A.; WENDLING, I.; SILVA, R. L. Silvicultura clonal: princípios e técnicas. Viçosa: Editora UFV, 2009. $272 \mathrm{p}$. 
FLORESTA, Curitiba, PR, v. 45, n. 1, p. 65 - 74, jan. / mar. 2015. Corrêa, P. R. R. et al. 